\title{
Explicit Language Teaching and Competence in Using the Past Tense in English among Saudi EFL Learners
}

\begin{abstract}
Sami Alanazi
\section{Abstract}

It has been well-established in research that Saudi Arabian EFL students tend to find it difficult to understand English tenses. In particular, they struggle with conjugating verbs in the past tense. This research examines how explicit grammar teaching could help undergraduate level Saudi students overcome these difficulties. For the study, students were put into two different groups. These were the experimental group (group A) and the control group (group B). Group A students were given direct, specific teaching focused on learning the past-tense. Group B students were given more general teaching. At the end of the study, they were tested. The results of these tests demonstrate a definite short-term improvement in the ability of group A students, but later testing indicates that this improvement may have been short-lived.
\end{abstract}

Key words: explicit teaching, grammar, EFL, ELT, SLA

\subsection{Introduction}

Hulstijin (2005, p.131) defines the explicit learning of a language as "input processing with the conscious intention to find out whether the input information contains regularities and, if so, to work out the concepts and rules with which these regularities can be captured". N. Ellis (1994) states that for language learning to be defined as explicit, it must be a conscious process. R Ellis (2008) also states that it is a conscious way of learning, in which students deliberately work to remember things they've learned. It may be that explicit language learning is better suited to adult learners' brain structures than implicit language learning (DeKeyser, 2000; DeKeyser \& Larson-Hall, 2005).

Explicit and implicit learning can be seen as opposites. Implicit learning is not conscious or deliberate. Richards and Schmidt (2010) further defined the differences between the two modes of learning as follows:

1) The use of tests and the creation of hypotheses are both common in explicit learning, but not used at all in implicit learning.

2) Explicit learning depends on students setting out to learn in a structured, purposeful manner, whereas implicit learning happens naturally, without structure or set goals.

3) Implicit learning does not aim to increase conscious understanding, but explicit learning does.

Implicit learning is defined as "input processing without such an intention" (Hulstijn, 2005:131). It happens without the student realizing that they are learning and without any external intervention.

Some scholars believe that implicit learning is far less effective than explicit learning. Norris and Ortega (2000) state that:

1) Teaching provides students with considerable value.

2) The value of taught learning continues to be evident over a long period of time.

3) Implicit learning is not as effective as explicit.

When it comes to the teaching of grammar, explicit learning involves students repeating particular, directed learning assignments. Students are expected to follow instructions, and there is little space for them to actively direct their own learning. They may be able to make a more active contribution after they have proved the knowledge they have gained from directed learning.

\section{Forms of knowledge}

Studies on second language acquisition provide insight into how students learn new languages, including the benefits of both explicit and implicit learning, and the ways in which these two types of learning can interact. Three viewpoints on this issue have been established.

1) Krashen's view is that explicit learning does not lead to implicit understanding.

2) Paradis also believes that there is little or no interaction between the two types of learning and understanding, stating that "explicit knowledge and implicit competence do not share information; they do not exchange data: they do not interact".

3) DeKeyser, in contrast, states that the two types of learning interact significantly.

\subsection{Explicit knowledge}

Explicit learning is the declared understanding of facts that students know they are acquiring (Ellis, 2005; Bowles, 2011, Rebuschat\& Williams, 2013). R. Ellis (2009) also states that explicit learning is deliberate, used to observe and correct words consciously. So, a student reads an incorrect sentence, and is able to provide a correct version by accessing the grammar knowledge they have gained via study. For example, they might change a sentence such as 'I see Emma yesterday' to 'I saw Emma yesterday'. They're able to do this because they understand the relevant grammar rule. Over 
time, repeatedly changing incorrect sentences using explicit learning and lead to implicit competence, where the students will not have to consciously recall grammar rules to correct a sentence (Smith, 1981; DeKeyser, 1998, 2007).

\subsection{Implicit knowledge}

Students use facts that they have gained implicitly constantly, without realizing what they are doing or being able to explain their knowledge. (Ellis, 2005; Bowles, 2011; Rebuschat and Williams, 2012). They might sometimes understand that a particular sentence uses bad grammar, but be unable to indicate exactly what about that sentence is problematic.

\subsection{The study}

\subsection{Aims}

This research looks at how explicit learning contributes to understanding of past-tense verbs. It studies Saudi Arabian English as a Foreign Language, giving students comprehension exercises to evaluate their level of understanding.

\subsection{Hypotheses}

This study uses the following hypothesis:

Students who are provided with explicit teaching will have better knowledge of past tense verbs than other students.

\subsection{Study participants}

The students used for the research had been studying English for eight years, prior to beginning university courses in Saudi Arabia. All the students were native Saudis. For the purposes of the study, they were put into two groups, an experimental group (group A) and a control group (group B).

\subsection{Tasks and intervention}

The students were given tests to establish their levels of knowledge at different stages. They were tested before the study began, immediately after the study, and a few weeks later. The tests all included thirty questions related to English past tense verbs. The test questions were split evenly between the perfect, progressive and simple past tense.

The first test, conducted before the study, established the students' initial level of knowledge before they were provided with teaching as part of the study. When they had received this teaching, they were tested again to establish what difference it had made, and whether the students who had received explicit teaching fared better than those who had not. The final test was given two weeks after the study finished, to establish how much of the students' new knowledge was retained.

The teaching given during the study was split over two lessons. It used exercises in past tense English verbs taken from the New Headway elementary level book. This book is used to deliver the English Language 101 course.

\subsection{Procedure and data analysis.}

The students were given information about how the study would be conducted and how their data would be used by the researchers. They were told that they could decide to stop participating before the study's end if they chose to do so. Before they could take part, they were asked to sign a consent form.

The students were tested three times during the study, as outlined earlier. Students in the experimental group A, were given a two-hour lesson on past tense verbs, using explicit teaching. Their lesson included direct instruction on the past perfect, past progressive and past simple tenses. They were provided with usage models for all three tenses. Those in the control group B, were given a lesson on the same subject, that did not use explicit teaching. Both groups were taught in a standard classroom environment. The students were tested just after they were taught and then again three weeks after the teaching.

The information gathered from the testing of each group was fed into SPSS software. An ANOVA test was used to examine the results, looking at both a comparison of the experimental and control groups, and a comparison of the different tests made within each group.

\subsection{Results}

There were three tests used in the research, all of which were given to both groups of students. Each group consisted of 20 students. Those in group A were taught using explicit methods, while those in group B were not. The same material was covered by each.

Table 1 summarizes the results of the tests given before and immediately after teaching. It shows that there was an increase in score after teaching for both groups, as would be expected, but that the increase was larger for group A than group B. 


\begin{tabular}{lll} 
Group & Pretest & Post-test \\
Group A (experimenta1 group) & 4.33 & 4.83 \\
Group B (control group) & 4.25 & 4.41 \\
\hline
\end{tabular}

Table 1: comparing the results of the pre-test and post-test for both groups $(n=40)$

While the experimental group demonstrated a larger increase in score after teaching than the control group, this difference was small and not statistically significant. Looking at the results of the test given weeks after the teaching provides a clearer picture.

Table 2 summarizes the results of all three tests. It shows that while the experimental group showed a larger increase in score between the first and second tests, this increase was not sustained at the time of the third test.

\begin{tabular}{llll}
\hline Group & Pre-test & Post-test & Delayed test \\
Group A (experimental group) & 4.33 & 4.83 & 4.62 \\
Group B (control group) & 4.40 & 4.32 & 4.43 \\
\hline
\end{tabular}

Table 2: comparing the results of the three test stages for both groups $(n=40)$

The study's results demonstrate that it is helpful to students to be given explicit instruction, and that they can gain an immediate increase in their knowledge and ability as a result. It also shows that this increase is not sustained long-term, and so the hypothesis is not proven. The study also demonstrates that students' understanding of language is influenced by their understanding of grammar.

\subsection{Conclusion}

Scholars disagree on whether the use of explicit teaching methods is a more effective way to teach language skills than other methods. This study aimed to establish whether explicit teaching was more effective when tested on a group of Saudi Arabian students learning about past tense verbs.

The study found that explicit teaching methods resulted in a small, temporary increase in test scores, when compared to students taught using other methods. The students in the experimental group retained some of their new knowledge over time, but they did not retain enough to show a sustained advantage over the control group.

In Saudi Arabia, teachers generally believe that using the first language to teach a second language is damaging to students' progress. I believe that it is unclear whether this is the case, and that there is a need for further research.

\section{References}

Adair-Hauck B., Willingham-McLain, L., \& Youngs, B. E. (2000). Evaluating the integra- tion of technology and second language learning. CALICO Journal, 17, 269- 306.

Bowles, M. A. (2011). Measuring Implicit and Explicit Linguistic Knowledge. Studies in Second Language Acquisition, 33(02), 247-271. doi:10.1017/s0272263110000756

Dekeyser, R. M. (1998). Beyond focus on form: cognitive perspectives on learning and practicing second language grammar. In C. Doughty, \& J. Williams (Eds.), Focus on form in second language acquisition (pp. 342-359). Cambridge: Cambridge University Press.

DeKeyser, R. (2000). The robustness of critical period effects in second language acquisition. SSLA, 22,499 - 533.

DeKeyser, R. (2003). Implicit and Explicit Learning. In C. Doughty \& M. Long (Eds.), The Handbook of Second Language Acquisition. Malden, MA: Blackwell Publishers.

DeKeyser, R., \& Larson-Hall, J. (2005) What Does the Critical Period Really Mean? In: Kroll, JF, De Groot AMB, eds. Handbook of Bilingualism: Psycholinguistic Approaches. Oxford: Oxford University Press. pp 88-108.

Ellis, R. (2005). Measuring Implicit and Explicit Knowledge of A Second Language: A Psychometric Study. Studies in Second Language Acquisition,27(02), . doi:10.1017/s0272263105050096

Ellis, R. (2008). The study of Second language acquisition (2nd ed.). Oxford: Oxford University Press.

Hulstjin, J. H. (2005). Theoretical and empirical issues in the study of implicit and explicit second- language learning. Studies in Second Language Acquisition, 27, 129-140.

Krashen, S. (1981). Second language acquisition and second language learning. Oxford: Pergamon Press. 
Paradis, M. (2009). Declarative and procedural determinants of second languages. Amsterdam: John Benjamins.

Richards, J. C., \& Schmidt, R. W. (2010). Longman dictionary of language teaching and applied linguistics (4th ed.). Harlow, England: Pearson College Div.

Rebuschat, P., \& Williams, J. N. (2012). Implicit Learning in Second language acquisition. The Encyclopedia of Applied Linguistics.

Schmidt, R. (2001). Attention. In P. Robinson (Ed.). Cognition and second language instruction (pp.3- 32). Cambridge: Cambridge University Press.

(c)

This work is licensed under a Creative Commons Attribution 4.0 International License. 